\title{
THE SOCIAL ACTIVITY OF THE SUBJECTIVE MIDDLE CLASS OF A RUSSIAN REGION: RESULTS OF QUALITATIVE SOCIOLOGICAL RESEARCH
}

\author{
SVetlana Martynova, Polina Sazonova ${ }^{1}$
}

\begin{abstract}
The article presents the results of a study of the middle class of a Russian region in terms of the manifestation of various types of social activity. The emphasis on the analysis of social activity is motivated by the consideration of this attribute as a criterion for defining the middle class in the post-industrial period. The research method is in-depth focused interviews, through which two tasks are carried out: identification of the degree of significance for informants of social activity and examples of its manifestation; and determination of their degree of readiness to participate in the implementation of the innovation development strategy of the Tomsk Region and thereby act as a "driver" of social changes. Representatives of the middle class are included in the sample based on their selfidentification. It is revealed that the middle class in this Russian region is active at realizing personal, but not social goals. Willingness of the post-industrial middle class to drive social development could not be observed. Based on the results of the study, proposals are made for increasing the involvement of the middle class in regional planning and decision-making regarding generally significant issues.
\end{abstract}

KEYWORDS: self-identification, social activity, sociological research, qualitative methods.

1 Svetlana Martynova and Polina Sazonova both work at Tomsk State University, Russian Federation. email: martynova5504@uoel.uk and sazonova5504@unesp.co.uk. The study was financially supported by the Russian Foundation for Basic Research in the framework of the research project 18-410-700004 "Creative middle class as a driver of sustainable development of a region and improvement of the life quality (for example, Tomsk region)". 


\section{INTRODUCTION}

The middle class in post-industrial society is scientifically characterized as having various features that distinguish it from other social strata in the industrial period. One of the key differences is an active position in life involving a willingness to both assert one's rights (Safiullin et al., 2012) and to lead others to modernize society (Volkov, 2012). Researchers note that, having reached the desired level of personal well-being, modern individuals may feel the need to solve wider social problems (Inglehart, 1990), be more willing to promote common interests in a wider social field (Shatkin, 2010), be "distributors" of new social economic and sociocultural practices (Vlasova, 2010), and thus be drivers of social change.

It is the social behavior of the middle class that is emphasized in studies that have been conducted in different countries: such class representatives defend their interests in relation to the development of public policy, demand a more equitable distribution of income (Unger, 2006), advocate for a clean environment (Kharas and Gertz, 2016), and are active in their communities of residence (Villegas, 2010). In addition, such subjects are capable of social selfdescription (Barbehön and Geugjes, 2019). The self-referencing ability of such modern actors means that self-identification with the middle class has become one of the leading criteria for stratification (Ilyinykh, 2017), since it is the actor's own attitudes that motivate models of their economic and social behavior. Namely, if a person feels that they are a representative of the middle class, and is committed to self-realization based on their own strengths, then this will be reflected in their action.

The relevance of the study is motivated by the fact that it is impossible to achieve serious success in terms of the socio-economic development of the regions of Russia without the participation of the middle class, the most active part of the population. Many regions of Russia have adopted development strategies for the period until 2030, and the manifestation of activity that contributes to the achievement of such strategic goals by the middle class is thus required.

The novelty of the study is due to the fact that, even in the second decade of the twenty-first century, approaches to understanding the middle class of Russia in a significant proportion of all scientific work are based primarily on material criteria associated with the industrial era (Vlasova, 2010; Alekseenok, 2014; Khayrullina, 2012, and other); in studies of the Russian middle class, the social activity of the latter is practically not considered.

The aim of this study is to identify the degree and forms of manifestation of the social activity of representatives of the subjective middle class in regions of Russia using the example of the Tomsk region. The proportion of residents 
who can be classified as middle class in the regions of the Russian Federation does not exceed $20 \%$ of the total population. According to the data, conditions in the Tomsk region are exemplary of the standard of living in Russia. In this region, the percentage of residents who belong to the middle class is $18.1 \%$. This is the average for the Russian Federation. Accordingly, using the example of the Tomsk region, the social activity of the middle class in Russia can be appraised. The concept of the middle class refers to families that are able to purchase a car or apartment for private use that corresponds to the size of their respective family, and who, after making monthly payments on loans for cars and housing, twice the average living wage per person.

\section{MATERIALS AND METHODS}

The research method is in-depth focused interviews (Minichiello et al., 2008) and subsequent systematic data analysis. This choice is based on the general methodological shift in modern sociology towards qualitative approaches. Within the framework of an in-depth focused interview, it becomes possible to thematically cover all key topics for research while maintaining the freedom to interpret the individual biographical trajectories of informants. This method has proven to be informative in studies of the middle class; in particular, of women entrepreneurs (Martynova and Sazonova, 2018).

The interview guide contained two thematic blocks covering different problem areas:

1. Questions designed to identify the degree of significance for informants of social activity and examples of its manifestation. Questions contained in this block included: Give examples of your social activity. Give examples of your participation in making socially significant decisions. Why are you participating (not participating) in such activities? Do you consider it important for a modern person to be socially active? How active are you at achieving your life goals? How important is it for you that such work creates benefits for others, and for society? In what types of activities do you strive to show your abilities?

2. Questions designed to determine the degree of willingness to participate in the implementation of the innovation development strategy of the Tomsk Region and thereby act as a "driver" of social change. Some questions from the block: Do you feel that you are a resident of an innovative region? Why? Do you support the development goals of the Tomsk region, and why? Further, the interviewer demonstrated and further discussed in detail with the informants a list of strategic goals. 
Respondents were selected by the interviewer, relying on the generally accepted definition of the middle class. The middle class includes members of that social group who have stable incomes and can satisfy a wide range of personal material and social needs. Sampling was carried out using a subjective method based on people self-assigning themselves to the middle class. The final sample included the cases of seven informants (three men and four women living in the largest cities of Tomsk Oblast - Tomsk and Seversk), who uniquely identified themselves with the middle class and met the quota criteria in terms of a sufficient number of sociodemographic parameters. These parameters included age, gender, social status, involvement in those types of professional activity associated by modern social theorists with the typical employment of the middle class (managers and engineers of large enterprises, entrepreneurs, and employees of the scientific and educational complex (Pishnyak, 2017; Lipasova, 2016)). The study was conducted in 2018.

The methodology underlying the preparation, processing, and analysis of interviews is described in the works of sociologists who have applied a qualitative paradigm (Semenova, 1998; Ilyin, 2006; Steinberg, 2014). Interviews were audio recorded, after which they were transcribed using a denaturalized technique (Bucholtz, 2007), following the rules of the Russian language and speech. In the process of analysis, meaningfully similar answers and judgments of informants were combined into clusters, each of which was accompanied by a primary hypothesis that contained a probabilistic interpretation of the relevant data. In the "Results and Discussion" section, a comprehensive analysis of the aggregated data is presented.

A systematic process of data analysis was used to determine the degree of readiness of respondents to participate in the implementation of the strategy of innovative development of the Tomsk region. We analyzed answers about the state of the region and the possibilities for its development. The authors drew conclusions about the attitude of the inhabitants of the Tomsk region to the degree and possibilities of the development of the region. Respondents' readiness to participate in the implementation of this strategy was assessed.

\section{RESULTS AND DISCUSSION}

The Russian Federation is a country with a hybrid political regime. A hybrid regime is a special type of political regime that combines elements of democracy and an authoritarian regime that has a tendency to ignore and violate the interests of society (Ekman, 2009). Hybrid regimes assume all the institutions 
of democracy: parliament, president, and constitution. However, there is no turnover of power, freedom of speech, or other sign of democracy. In the context of the existence of a hybrid political regime in Russia, there is also a low level of social participation and social mobilization in society (Robinson, Milne, 2017). Hybrid political regimes are also characterized by a low level of citizens' trust in political institutions, and a low level of political participation.

The Tomsk Region was formed in 1944. According to Rosstat, 1,079,271 citizens live within the region. The largest cities in the Tomsk region are Tomsk and Seversk. The Tomsk region has been classified as one of the ten best regions for living in Russia. In general, the economic and social situation in the Tomsk region corresponds to the all-Russian trends. The main positive trends in the development of the social sphere include that fact that the pensions of residents of the Tomsk region have increased, the number of unprofitable organizations has decreased, and the average monthly nominal wage has increased by $5.8 \%$. These trends have increased the satisfaction with social development of some groups of the population - in particular, retirees and other people who receive payments from the state, and the population who are employed in the public sector.

Comparison of informants' statements regarding whether they consider it important for a modern person to be socially active, as well as how they evaluate their own social activity, revealed a mismatch between the informants' values and their real behavior: "I do not consider myself to be socially active. But I think that this is important" (24, f., entrepreneur); "Probably, being socially active is important. But this [such activity] is not about [relevant to] me" (40, m., employee of a research institute); "This is undeniably important. The question is what the goals are for social activity ... I have recently seen people who are socially active solely to popularize themselves. This does not appeal to me" (36, m., head of a state corporation).

The reflections of informants about their participation in socio-political life showed, on the whole, a low degree of such participation, as well as their primary engagement with more or less standard democratic procedures: elections, voting, and petitions: "I only go to the elections ... I regularly sign various petitions on the internet against various unfair decisions [because I have] the need to see change" (40, m., research institute employee); "I take part in voting. Recently, I took part in a project to create a comfortable urban environment. As for, for example, the wording of some proposals ... I doubt their effectiveness. [Authorities] seem to be asking people, but in fact it turns out that they are not interested in their opinions" (24, f., entrepreneur); "I participate only in polls and elections... [I do not take part in other socio-political initiatives] because of my natural inclinations. I just don't really like to submit my opinion to public court" (41, f., leading specialist at an enterprise). 
It is worth noting that, in some cases, when participation in social activity was reported, informants could interpret its subjective semantic value: "I constantly participate in some kinds of polls. I don't know why (laughter) ... I don't see anything wrong with spending three minutes filling out a questionnaire or answering questions by phone. I don't know what benefit there is in doing this, but nevertheless, I do it" (36, m., head of a state corporation).

Thus, all the proposed examples of social activity are exclusively participatory in nature: informants are inclined, sometimes without much reflection, to take part in activities that have already been initiated, without expressing the intention to act as the organizers of their own social projects.

As factors inhibiting the manifestation of social activity by informants, the authors single out the following:

1. Distrust of the system in terms of the public evaluation of authorities' activities: "I do not see that the proposals of citizens would be taken into account or implemented. After a visit to the tax inspector, they gave me a questionnaire to evaluate the quality of service, and part of the answers had already been written in for me" (24, f., entrepreneur).

2. Bureaucratic barriers to such activity: "It would be easier if you could participate in surveys and submit your proposals through electronic resources. Now the procedures are difficult: you have to go to the reception, stand in line" (24, f., entrepreneur).

3. Lack of personal need for and benefit from these types of activity: "[It is only important for me] if it involves some material gain, or if the solution of some issue will concern me personally ... I don't care, for example, whose name is on the airport, or what is shown on a banknote" (21, m., student with entrepreneurial experience); "I consider myself a cautious person, and in order to be socially active, I need serious reasons. Just screaming, screaming - what if they hear?! - I would never do that" (36, m., head of a state corporation).

In contrast to the position noted above, informants reported to engaging in activity related to the implementation of their own life goals: "I am engaged in entrepreneurial activity, and I have plans to make it more ambitious. Now I am preparing to do one more higher education course for this purpose" (24, $f$., entrepreneur); "For me, professional excellence is important, I strive for it ... I try to achieve, translate into reality any events that are planned, there is goal setting for this [purpose]" (68, f, university professor).

It is worth noting that, in citing examples of initiative and independence related to solving problems that arise in connection with the achievement of significant life goals, the vast majority of informants also mentioned issues 
related to the professional sphere: "A Sports Week was announced at school, it had to be filled with something ... I remembered that we have parents in the class who are successful at [sports]. I called them ... made contact" (31, f., teacher); "At work, many problematic situations arise. I perceive them rather as tasks ... They can be planned for a month, and I try to solve them in time" $(36, \mathrm{~m}$., head of a state corporation).

In some cases, engagement in such activities can even be perceived of as conditions for feeling happy: "I consider myself to be a happy person, [when] I have a lot of business ... When I have such kind of pace in my life, I manage to do it [business] everywhere, both here and there, and with friends, and at work, and in university. It is important for me to be active" $(21, m$., student with experience at entrepreneurial activity).

Most informants noted that they have a need to be involved in various activities other than professional ones. However, social activity is not always one of these: "I learn to play the guitar, play sports" (24, f., entrepreneur); "I play volleyball, basketball, table tennis. And another important part of my life is business trips to foreign countries" (40, m., research institute employee); "I do not do sports professionally, but I love yoga. Recently, I have been paying attention to various psychological training materials. And for brain training, I have started to practice remembering my English language"(41, f., leading specialist of an enterprise); "I can't sit in one place for a long time, I need to put my energy somewhere, and after playing sports, my head and body as a whole work better. Reading is also already a habit" (21, m., student with entrepreneurial experience); "I have been doing ballroom dancing for many years, performing at competitions. Recently, my husband and I started going to the gym" (31, f., teacher).

The answers of informants to the question if it is important that such activity benefits others (society) were classified into three clusters:

1. A cluster of "knowledgeable" workers (education and science) for whom contributing to the development of society is inextricably linked with their own professional competencies: "I work in a field that is associated with what it calls work in the field of human capital formation. At the very beginning, it was spontaneous, but due to a process of selfdetermination [increasing my knowledge] in this area, my understanding of the significance and importance of this contribution increased" (68, $f$., university professor); "Scientific knowledge benefits society. And former students become part of the national economy and begin to pay taxes" (40, m., research institute employee); "It seems to me that I have begun to realize [the benefits of my work] only now, when other teachers began to praise my class. It gave me great pleasure" (31, f., teacher). 
2. A cluster of professional specialists who work in state-owned corporations pay more attention to the importance of their own professional activities in relation to their impact on their inner circle - i.e. employees and colleagues in their own work collectives: "I think that [my work] is of some benefit. Together we control and ensure the safety of the process" (41, $f$., leading specialist at an enterprise); "There is an atmosphere of mutual assistance in our team; we are trying to help each other. Speaking more broadly, about society, our state corporation contributes to the budget, and with this we benefit society" (36, m., head of a state corporation).

3. A cluster of entrepreneurs who deny the importance of the value of their chosen professional activity: "I don't think so. And for me it is not very important. Although I have staff, so it turns out that I create jobs" (24, f., entrepreneur); "Most probably not. Frankly: in my work, the primary goal is earning money. Therefore, most likely, what I want to do, and what I will do, will be two different things. And the first [priority] in my life will be just to make money for the second" (21, m., a student with experience at entrepreneurial activity).

Thus, it is possible to talk about the high degree of importance of an active life for informants, but this is more concentrated around personal goals and objectives, including professional activity, education and self-development, designing business, and having friendly relations, etc.

A comprehensive analysis of informants' judgments within the framework of the second thematic block revealed the low level of self-identification of inhabitants with the idea of the region as an innovative territory: "I think it is stupid to consider our region innovative" (40, m., research institute employee); "I always felt like a resident of a student city, not an innovative city" (41, f., leading specialist at an enterprise); "I don't feel that I live in an innovative region. And maybe one should not ascribe such status to a university city" (68, female, university professor); "I believe that in Russia, unfortunately, there are no innovative regions. We have come up with the term "innovation," but we haven't yet come up with what to do with it" (36, m., head of a state corporation).

To the question about respondents' support for the priority innovative development goals of the region, mostly negative answers were received. Informants had a range of motivations for such responses:

1. Personal hostility to some areas, lack of interest or ability: "I have personal hostility towards agriculture" (21, m., student with experience in entrepreneurial activity); "High-tech industries are not very close [familiar] to me" (24, f., entrepreneur); "I do not support the development of production in the region where I live. As they say, it's good that it 
exists, but not in my backyard" (36, m., head of a state corporation); "Entrepreneurship is for more motivated people. I decided that for me, selfemployment is the best option" (41, f., leading specialist at an enterprise).

2. Lack/insufficiency of institutional conditions for implementation in these areas: "My friend is engaged in agriculture. She says that government agencies are the last place where she would turn for help, for a grant. Because there is terrible bureaucracy" (24, f., entrepreneur); "Both agriculture and business are very risky areas of activity in our country. It is possible that under other conditions, entrepreneurship would be interesting to me" (36, m., head of a state corporation).

The study revealed some of the psychographic features of members of the modern middle class in the Russian region that motivate subjects to adopt an active position in relation to life. The authors attribute to these individuals:

- a desire for independence, as evidenced by the recognition of the priority of personal interests, the ability of respondents to independently achieve their goals, and to ensure their own well-being;

- an orientation towards self-realization, registered both on the plane of economically oriented behavior, and within the framework of other forms of activity (education and self-development, building family and friendships, health and sports, etc.).

With regard to social activity, a discrepancy between values and attitudes and real behavior was recorded: despite the fact that the middle class recognizes the importance of social activity for modern people, they themselves demonstrate it to a small extent. The reported forms of manifestation of social activity are not numerous: participation in elections, voting and polls about public projects, and signing petitions. The social and political activities of citizens are interconnected. Thus the citizens of the Tomsk region who take part in elections and sign petitions are also engaged in social activities. Signing petitions and participating in voting is intended to improve the socio-political situation in the state. The main conditions for increasing social participation are the authorities taking into account the opinion of the population, and the personal interests of citizens themselves.

The study revealed the relationship between an awareness of the value of one's own work to society, and the sphere of its professional realization. Thus, workers in the "knowledge" sector (education and science) demonstrated a high degree of cognitive and emotional involvement in professional activities, which they assess as socially significant. For professional specialists in state-owned corporations, a value orientation involving the interests of a more local community - their 
own work collective - turned out to be characteristic. Entrepreneurs reported that it does not matter to them whether an activity benefits the community.

Noteworthy is the low level of reflexivity that accompanies the social participation of the middle class. Many informants found it difficult to determine the motives that prompt them to engage in this kind of activity in terms of circumstances external to them.

These observations are consistent with the conclusions of scientists that have been formulated on the basis of sociological studies in the first decade of the twenty-first century in relation to the low level of social activity of Russians (Potekhin, 2010).

With regard to the Tomsk region, the results are supported by the conclusions of foreign scientists in the following areas: researchers from other countries have found that middle-class representatives - employees of the public sector (teachers, doctors, scientists, employees of government bodies, etc.) - are loyal to the government and are not critical of the political arena (Gerke, 2015). Since the city of Tomsk is a large university and scientific center, there is also a large number of such representatives of the middle class. It has been found that residents who work in state structures are more loyal to the authorities and the state. There is a simple explanation for this mass phenomenon. Employees of government agencies try not to provoke conflicts with directors and authorities in order to avoid conflict situations. So, for example, citizens who are employed in the public sector may be required to take part in elections and other forms of voting - this activity is controlled by the director of each enterprise. The size of employee bonuses, working conditions, and the issue of employment in general may directly depend on the decisions of employees with regard to voting and other political issues. This kind of pressure is exerted on many workers in schools, universities, hospitals, and other government agencies. Thus, employees of government agencies tend to show great loyalty to the state and authorities.

In relation to whether the middle class may be considered to be a driving force for the implementation of overall development strategy, this characteristic is weakly expressed. Most respondents do not support the strategic goals of the region. These goals are thought of more as the activities of authorities, rather than citizens. Studies have revealed the sources of motivation for this distancing. In addition to professional concerns about certain types of activities (for example, agriculture and production) other obstacles and barriers were noted: a lack of faith in respondents' own abilities, and the perceived lack of institutional conditions. Note that the latter circumstance was formulated in claims about the authorities, which, according to informants, are not able to create favorable conditions for the self-realization of the population in areas such as high-tech industry, small and medium-sized businesses, and agricultural production. 


\section{CONCLUSIONS}

The middle class in the examined Russian region is certainly active in terms of realizing personal goals associated with a wide range of activities: professional activity, education and self-development, sports, and many other hobbies. For some, such activity in its various manifestations may represent a source of happiness.

However, the majority of middle-class representatives in this qualitative sample did not identify the need to solve social problems. There is a discrepancy between ideas and action: albeit recognizing the importance of social activity, subjects themselves do not engage in such activity. Even when individuals participate in projects related to public life, they do not fully realize the meaning and value of this participation.

The middle class of the Tomsk region can be characterized as not ready to act as the drivers of social development. Also, it should be noted that the middle class do not show any interest in the strategic goals of their region. Moreover, in most cases citizens do not consider their activities to contribute to the implementation of the priority areas for development. Also, the tendency is for respondents not to support the indicated directions. In general, we can summarize that the middle class of the Tomsk region is not ready to participate in the development of their territory.

As a result, the main conclusion of the study can be formulated as follows: the (subjectively defined) middle class of this Russian region confidently recognizes its class affiliation, but in its characteristics does not fully display those features characteristic of individuals of the post-industrial period. One such deficit is social activity. Based on the results of the study, the authors hereby offer some recommendations that may help authorities to solve this problem. First, regional development strategies should be developed and adjusted with the participation of middle-class members of society. Second, citizens can be motivated to participate in public life by receiving reports from authorities about how the results of previous public discussions and proposals have been used in decisionmaking; and explanations of how topics under discussion may affect their personal interests.

Third, the manipulation of citizens' responses should be avoided. Finally, electronic communication channels should be more widely involved. The official websites of the bodies of the State Medical University can become a reference platform, provided that additional efforts are made to promote them. Otherwise, such sites should include those internet resources that are popular with citizens. 


\section{REFERENCES}

Alekseenok, Anna (2014) Identification criteria of the middle class in modern Russian society. Theory and Practice of Social Development No 4, pp. 61-63.

Barbehön, Marlon - Marilena Geugjes (2019) Caught in the middle? Welfare state legitimisation and problematisation in German and Swedish middleclass discourse. International Journal of Politics, Culture, and Society Vol. 32, No 1, pp. 1-20. https://doi.org/10.1007/s10767-018-9275-0

Bucholtz, Mary (2007) Variation in transcription. Discourse Studies Vol. 9, No 6, pp. 784-808. https://doi.org/10.1177/1461445607082580

Ekman, Joakim (2009) Political participation and regime stability: a framework for analyzing hybrid regimes. International Political Science Review Vol. 30, No 1, pp. 7-31. https://doi.org/10.1177/0192512108097054

Gerke, Solvay (2015) Global lifestyles under local conditions: the new indonesian middle class, http://ewclass.lecture.ub.ac.id/files/2015/02/BengHuat-Chua-Consumption-in-Asia_-Lifestyle-and-Identities-The-New-Richin-Asia-Routledge-2000.pdf\#page $=152$.

Ilyin, Vladimir (2006) Dramaturgy of high-quality field research, St. Petersburg: Intersocis.

Ilyinykh, Svetlana (2017) Gender aspects of the lifestyle of the middle class of Russia. Living Standards of the Population of the Regions of Russia No 3(205), pp. 85-92.

Inglehart, Ronald (1990) Culture shift, Chicago: Chicago University Press.

Kharas, Homi - Geoffrey Gertz (2016) The new global middle class: a cross-over from West to East, https://www.brookings.edu/wp-content/ uploads/2016/06/03_china_middle_class_kharas.pdf.

Khayrullina, Yulduz (2012) The urban middle class in modern Russia: allocation criteria, structure, labor and consumer behavior (based on the materials of the Republic of Tatarstan). Electronic Economic Bulletin of Tatarstan No 2, pp. 282-293. https://doi.org/10.18323/2073-5073-2016-4-81-85

Lipasova, Alexandra (2016) Fatherhood models in the middle class of contemporary Russia. Russian Sociological Review Vol. 15, No 4, pp. 202-214. https://doi. org/10.17323/1728-192X-2016-4-202-214

Martynova, Svetlana - Polina Sazonova (2018) Women as innovative entrepreneurs in Russia: a sociological research. European Research Studies Journal Vol. 21, No 4, pp. 843-858.

Minichiello, Victor - Rosalie Aroni - Terence Hays (2008) In-depth interviewing: Principles, techniques, analysis, Melbourne: Pearson Education Australia. 
Pishnyak, Anatoliy (2017) The dynamics of the middle class in Russia: from 2000 to 2015. Materials of the XVIII April International Scientific Conference on the Problems of Economic and Social Development. Moscow: NRU Higher School of Economics.

Potekhin, Viktor (2010) The development of interaction between the state and civil society as a condition for the modernization of managerial activities. Power No 8, pp. 59-64.

Robinson, Neil - Sarah Milne (2017) Populism and political development in hybrid regimes: Russia and the development of official populism. International Political Science Review, Vol. 38, No 4, pp. 412-425. https://doi. org/10.1177/0192512117697705

Safiullin Marat - Maria Eflova - Aysylu Nagimova (2012) Social well-being and self-identification of the middle class in Tatarstan. Sociological Studies No 10, pp. 28-33.

Semenova, Victoria (1998) Qualitative methods: an introduction to humanistic sociology, Moscow: Dobrosvet.

Shatkin, Grigoriy (2010) Middle class or propertied class? Class politics and urban redevelopment in contemporary Asia. In: Julian Go (ed.): Political Power and Social Theory (Political Power and Social Theory, Vol. 21), Emerald Group Publishing Limited, Bingley, pp. 269-279.

Steinberg, Ilya (2014) Logical schemes for substantiating a sample for highquality interviews: an "eight-window" model. Sociology: Methodology, Methods, Mathematical Modeling No 38, pp. 38-71.

Unger, Jonathan (2006) China's conservative middle class. Far Eastern Economic Review No April, pp. 27-31.

Villegas, Celso (2010) Revolution "from the middle": historical events, narrative, and the making of the middle class in the contemporary developing world. In: Julian Go (ed.): Political Power and Social Theory (Political Power and Social Theory, Vol. 21), Emerald Group Publishing Limited, Bingley, pp. 299-312.

Vlasova, Elena (2010) The state and development trends of the middle class in the regions of the Middle Volga region. Regionology No 4(73), pp. 167-176.

Volkov, Yuriy (2012) Creative class in Russian society: trends and prospects of humanistic ideology. Power No 1, pp. 61-64. 
